\title{
Immuned by Race: Ethnic Identity, Masculinity, and Attachment as Predictors of Cancer Screening among Black Men
}

\author{
Darlingtina K. Atakere, Tamara A. Baker \\ Department of Psychology, University of Kansas, Lawrence, KS, USA \\ Email: datakere@ku.edu, tbakerthomas@ku.edu
}

Received 6 May 2016; accepted 4 July 2016; published 7 July 2016

Copyright (C) 2016 by authors and Scientific Research Publishing Inc.

This work is licensed under the Creative Commons Attribution International License (CC BY). http://creativecommons.org/licenses/by/4.0/

\section{(c) (i) Open Access}

\begin{abstract}
An individual's motivation to screen for cancer is influenced by knowledge of cancer prevalence and perceived likelihood of being diagnosed. While the relationships between health and masculinity, identity, and attachment have been reported, much less is known as to how these factors influence the decision to screen for cancer. This study aimed to determine the influence identified health and social factors have on cancer screening among Black men. Participants $(N=369)$ were surveyed on questions assessing cancer knowledge, belief about cancer diagnoses, masculinity, self-esteem, attachment style, ethnic identity, and additional social and health characteristics. Results from the multivariate model showed that education, ethnic identity, masculinity, and attachment were significant indicators of cancer screening. Cancer screenings among Black men are contingent upon a myriad of psychological, social, and behavioral factors that are not exclusive, but rather coexisting determinants of health. Understanding the motivation for cancer screening among Black men may begin to diminish the prevalence of having an imminent and aggressive stage of diagnosis among this gendered population. Focusing exclusively on Black men enhances our understanding of this adult population by considering their identity as men of color, while recognizing unique factors that modify actions at the individual, institutional, and policy levels.
\end{abstract}

\section{Keywords}

Black Men, Cancer Screening, Masculinity, Attachment Pattern, Ethnic Identity

\section{Introduction}

There are a myriad of factors (e.g., access to health care, socio-economic status) that dictate health outcomes,

How to cite this paper: Atakere, D. K., \& Baker, T. A. (2016). Immuned by Race: Ethnic Identity, Masculinity, and Attachment as Predictors of Cancer Screening among Black Men. Psychology, 7, 1023-1033. 
quality of life, and longevity among the general population. While important, it is argued that modifiable health behaviors such as exercise, abstinence from smoking, and proper nutritional intake, are critical to health and longevity than non-modifiable factors (e.g., age, genetics). Defined as actions that influence health outcomes (e.g., medical check-ups; screenings), health behaviors, along with identified socio-demographic variables (e.g., education, marital status, sexual orientation, race, gender) are predictive characteristics of these outcomes (Calnan \& Rutter, 1986; Courtenay, 2000; Delva, O’Malley, \& Johnston, 2006; Kaplan, Newsom, McFarland, \& Lu, 2001).

While a number of public health and behavioral models have provided insight to the influence of these factors on individual and population health, there remains the question as to the underlying milieus that influence certain health outcomes among specific gendered and marginalized populations. In recent years, there has been a continued emphasis on the role social determinants of health (SDoH) domains have in explaining national and global health disparities. Social determinants of health are grounded in the circumstances by which individuals are born, grow up, live, work, and age (Braveman, 2015; Marmot, 2005; Marmot, Friel, Bell, Houweling, \& Taylor, 2008). They present as risk factors found in one's living and working conditions that predisposes the individual to disease or injury (Schulz \& Northridge, 2004). The fundamentals of these domains allow for a more dynamic and contextual framework to understanding race, social, and economic disparities in general, and gender-based differences in particular.

\section{Black Men and Health Outcomes}

Men are often socialized to project strength, individuality, autonomy, dominance, stoicism, physical aggression, and avoid any expression of emotion or vulnerability; all of which could be interpretedas weakness (Himmelstein \& Sanchez, 2014; Mankowski \& Maton, 2010; Williams, 2003). Beliefs on the socially contrived messages regarding masculinity and manhood are acknowledged in defining the behavioral patterns of men, which may have considerable consequences on health outcomes (Addis \& Mahalik, 2003). Health experts suggest that men are more likely to engage in riskier health behaviors that are considered characteristic of masculinity or normative expectations of being a man (Addis \& Mahalik, 2003; Harrison, Chin, \& Ficarrotto, 1992; Warner \& Brown, 2011). These social orientations and structural domains combine to increase risk-taking behaviors, emotional distress, and diminished health promoting behaviors (Mahalik, Pierre, \& Wan, 2006).

Black men in particular, have higher death rates of diabetes mellitus, stroke, and kidney disease than their White gendered counterparts (Centers for Disease Control, 2014). This is an important observation given the impact cancer (the $2^{\text {nd }}$ leading cause of death, 23.3\% among Black males), for example has on the abilities of the Black men to function physically, psychologically, and socially within the context of their environment (Baker \& Whitfield, 2006). In 2013, Black males had a higher age-adjusted SEER incidence rate of all cancers than White men (571.8 vs 508.2 per 100,000). Although this rate has decreased for Black men since 2000, the rate remains disparate compared to Whites and Black women (National Cancer Institute, 2016). These data are even more alarming as the latest (2013) incidence rates of prostate cancer are disproportionately higher for Black men compared to Whites (203.5 vs 121.9 per 100,000) (National Cancer Institute, 2016). Thus, what is ultimately gathered from scientific inquiry is that Black men have poorer health and health outcomes than the rest of the US population, and are exposed to an expansive range of social and environmental determinants that may have an adverse affect on their health, and identity as a man and a person of color.

\section{Social Identity and Health}

In addition to explaining the extent to which a person's existence as a member of a social group, influences group process and intergroup behavior, Social Identity theory provides explanation for the influence of groups and categorization on human behavior and psychological outcomes (Ellemers \& Haslam, 2011). According to Tajfel (1972), social identity is the "knowledge that [we] belong to certain social groups together with some emotional and value significance to [us] of this group membership” (p. 31). Haslam and colleagues (2009) posited that because individuals tend to understand and respond to the social structural conditions in which they find themselves, as well as define their sense of self according to the groups they belong, social identity can be linked to health outcomes.

Social identity can determine what a group considers as a normative healthy behavior to engage in, and how the members react to health messages proceeding from an 'out-group' (Cooper, Gonzales, Gallo, Rost, Meredith, 
Rubenstein, Wang, \& Ford, 2003; Oyserman, Fryberg, \& Yoder, 2007; Tucker \& Kelley, 2000). It has also been linked to processes that influence participation in health promotion activities (Laverie, 1998) and general wellbeing (Haslam, O’Brien, Jetten, Vormedal, \& Penna, 2005; Wegge, Van Dick, Fisher, Wecking, \& Moltzen, 2006).

Factors defining social identity can similarly be partnered with secure attachment. This provides a more cohesive framework to understanding health behaviors and outcomes, and predictive well-being and guided health practices among Black men. This duality may be found in Bowlby's (1982) attachment theory (Ciechanowski, Walker, Katon, \& Russo, 2002; Feeney, 2000; Mikulincer \& Shaver, 2007), which argues that dependence on the attachment figure(s) creates early experiences that are internalized, accentuating the enduring schemas of the self and others. As we come in contact with health care providers, a mental representation of relationships is ensued which, in turn, moderates how we perceive ourselves-as worthy of care or not, and whether others can be trusted to provide that care (Ciechanowski, Walker, Katon, \& Russo, 2002; Simpson, Rholes, Oriña, \& Grich, 2002; Ciechanowski, Sullivan, Jensen, Romano, \& Summers, 2003). Adults with a secure attachment style are shown to participate in preventive health behaviors more than those with an insecure attachment style (Armitage \& Harris, 2006; Huntsinger \& Luecken, 2004; Sakaluk \& Gillath, 2015).

Existent data describes the importance of cancer screening and early detection among the general population (Levin, Lieberman, McFarland, Smith, Brooks, Andrews et al, 2008; Smith, Cokinides, von Eschenbach, Levin, Cohen, Runowicz et al., 2002). While the impact and benefits of cancer screening has received overwhelming attention among majority populations, empirical evidence assessing factors that may serve as facilitators and/or barriers to cancer screening among older Black men is less evident. To contribute to our understanding of the complexity of normative behavior in cancer screening, this prospective study aimed to determine the significance demographic (age, education), health (cancer knowledge) and social characteristics (masculinity, ethnic identity, attachment, self-esteem) have on cancer screening among Black men. Determining the influence identified social factors have on perceptions and participation in cancer screening, beyond that of clinical and health indicators, is a strength of this study.

\section{Method}

\subsection{Participants and Procedure}

This study included a sample of men $(\mathrm{N}=369)$ who self-identified as Black or African American, able to read and understand English, and provide consent for study participation. Data were collected using Qualtrics links published on Amazon's Mechanical Turk (MTurk) website. Each survey lasted approximately 25 minutes, and respondents received a monetary gift for study participation. This investigation was approved by the university's Institutional Review Board.

\subsection{Measures}

Cancer screening. Current cancer early detection behavior was measured with a series of statements of the participant's current screening behaviors (e.g., screening without being told to do so, inspecting body for physical changes). Response choices to the statements were assessed on a four-point Likert scale ( $0=$ never to 3 = always). Respondents similarly responded to questions about their perceptions on perceived benefits of participating in cancer screening.

Social variables. The Males Role Norms Inventory-Short Form (MRNI-SF) is a 21-item questionnaire that assesses conformity to dominant cultural norms of masculinity (avoidance of femininity, negativity towards sexual minorities, self-reliance through mechanical skills, toughness, dominance, importance of sex, restrictive emotions). Respondents answered items on a seven-point Likert scale $(1=$ strongly disagree to $7=$ strongly agree) (Cronbach's $\alpha=.89$ ). High total scores indicate greater conformity to traditional norms of masculinity (Levant, Hall, \& Rankin, 2013).

Ethnic identity was assessed using the Multi-group Ethnic Identity Measure-Revised (MEIM) measure (Phinney \& Ong, 2007). The MEIM is a six-item questionnaire comprising two subscales: exploration (seeking out information about their own identity), and commitment (extent to which individuals feel attached to their ethnic group).In this study the cronbach's $\alpha$ for the scale is .76. Response choices ranged from 1 (strongly disagree) to 5 (strongly agree), which higher scores endorsing greater ethnic identity. 
The Experience in Close Relationships (ECR-16) scale was included to assess experiences in close relationships (i.e., secure attachment). This 16-item scale includes two sub-scales: avoidance (Cronbach's $\alpha=.66$ ) and anxiety (Cronbach's $\alpha=.86$ ) are structured to be included as two separate measurement scores, as opposed to one composite score. Responses for these questions range from 1 (disagree strongly) to 7 (agree strongly). Higher scores for both subscales indicate greater attachment insecurities (Lo, Walsh, Mikulincer, Gagliese, Zimmermann, \& Rodin, 2009).

Self-esteem was measured using the Rosenberg's Self-Esteem scale (RSE). This 10-item instrument is designed to measure global self-worth by assessing both positive and negative feelings about the self (Cronbach's $\alpha=.91$ ). Participants rate themselves using a five-point scale (1 strongly disagree to 5 strongly agree), with high scores suggesting greater rates of reported self-esteem (Rosenberg, 1965).

Beliefs about cancer diagnoses was measured by asking participants to report on their beliefs about Black men being diagnosed with cancer and how likely Black (and White) men will be diagnosed with cancer. Response choices ranged from "not very likely” (0) to “very likely” (2) (Cronbach’s $\alpha=.78$ ). A list of eight reasons for the participant's responses was included. Reasons for the responses ranged from Black men being tougher than White men to Black men eat healthier than White men. Respondents were instructed to check all those that apply.

Demographic Characteristics. Four demographic variables were included in the analyses: ethnicity, age, marital status, and education. Although the study was designed to only include Black men, participants were asked to self-identify their race group (Black/African American, White, Hispanic, Asian). Those who did not self-identify as Black/African American was excluded from study participation. Age was included as a continuous variable. Education was entered as a dichotomous variable ( $<12$ years; $\geq 12$ or more years of education). Marital status was categorized as married, living as married, separated, divorced and single/never married).

\subsection{Data Analytic Strategy}

Descriptive analyses were calculated to provide measure performance and a profile of the sample's demographic (age, education, marital status) and social (ethnic identity, self-esteem, attachment, masculinity) characteristics. Using pairwise deletion, a series of bivariate correlations were calculated to determine a parsimonious model ( $p$ $<.05$ ), and to determine the strength of the associations between current cancer screening and each study covariate. Ahierarchical regression analyses was further specified to determine the amount of unique variance in cancer screening accounted for by the demographic variables, and masculinity ethnic identity, self-esteem, and attachment. The regression procedure entered the predictor variables in three models. Demographic variables (age, education) were entered first (Model I), followed by identity and self-esteem (Model II). The remaining social variables (avoidance-attachment, anxious attachment, masculinity) were entered as the final set of predictor variables (Model III). Standardized beta coefficients were reported to describe the relative importance of the predictor variables within the regression model. Statistical significance was determined with the probability of a Type I error, $p \leq .05$. All statistical analyses were conducted using SPSS version 22.0 (SPSS Inc., Chicago, IL).

\section{Results}

\subsection{Sample Characteristics}

The study included sample of Black men, with a mean age of 33.6 (SD = 8.81) years. The majority of the sample (93\%) reported having more than 12 years of education, with more than one-third (38.9\%) being married. Of the total sample, only 22.5\% reported ever being screened for cancer. Prostate (81.1\%), followed by liver (51.5\%), kidney (42.0\%), and colorectal (36.0\%) cancers were thought to be the most common diagnoses among men. Approximately 43\% of the men reported that Black men were very likely to be diagnosed with cancer, and similarly reported feeling that as Black men, they are very likely to be diagnosed with cancer (51\%). Reported reasons for these beliefs included: Blacks and Whites have equal chances, Black men are tougher than Whites, and Black men are genetically different. Other demographic, health, and social characteristics are provided in Table 1.

\subsection{Associations of Cancer Screening with Study Covariates}

Results in Table 2 show a significant negative association between cancer screening and age $(\mathrm{r}=-.15, p<.01)$, 
Table 1. Demographic and social characteristics $(\mathrm{N}=369)$.

\begin{tabular}{lc}
\hline Variable & M \pm SD \\
\hline Age & $33.1 \pm 8.8$ \\
Gender (Male) & $100 \%$ \\
Ethnicity (Black) & $100 \%$ \\
Education (More than 12 years) & $93 \%$ \\
Marital Status (\% Married) & $39 \%$ \\
Diagnosed with cancer & \\
Family history of cancer & $95 \%$ \\
Know a male with cancer & $23 \%$ \\
Screen for cancer & $33 \%$ \\
Common cancer diagnoses in men & \\
Prostate & $23 \%$ \\
Liver & \\
Kidney & $81 \%$ \\
Colorectal & $52 \%$ \\
Cancer diagnosis belief & $42 \%$ \\
Black males likely to be diagnosed & $36 \%$ \\
Feeling as a Black to be diagnosed & $51 \%$ \\
Perception for cancer diagnosis belief & \\
\hline Blacks and white have equal chances & \\
\hline
\end{tabular}

${ }^{\mathrm{a}}$ Percentage that reported No.

Table 2. Association between cancer screening with study covariates.

\begin{tabular}{cc}
\hline Variable & $r$ \\
Age & $-.15^{*}$ \\
Education & $-.16^{*}$ \\
Masculinity & $-.2 .8^{*}$ \\
Identity & $.11^{* *}$ \\
Self-esteem & $.24^{*}$ \\
Avoidance & $.36^{*}$ \\
Anxious & -.10 \\
\hline
\end{tabular}

Pearson-Product Moment; ${ }^{*} p<.01 ;{ }^{* *} p<.05$.

education $(\mathrm{r}=-.16, p<.01)$, and masculinity $(\mathrm{r}=-.28, p<.01)$. Analyses further show cancer screening being moderately associated with avoidance-attachment $(\mathrm{r}=.36, p<.01)$. Significant positive correlations were found between cancer screening and ethnic identity $(\mathrm{r}=.10, p<.05)$ and self-esteem $(\mathrm{r}=.24, p<.01)$, suggesting that those with more positive feelings of themselves was associated with being screened for cancer. Similarly, men 
with a strong sense of ethnic identity was related to being screened for cancer $(r=0.11, p<.05)$. The anxiousattachment subscale was the only covariate not significantly associated with cancer screening.

\subsection{Multivariate Analysis}

A hierarchical multiple regression model was calculated to determine the amount of unique variance in cancer screening accounted for by the demographic and social variables. The first step in model development involved entering the demographic variables (age, education; Model I). These variables accounted for less than one percent of the total cancer screening variance. Although not accounting for much of the total variance, both age ( $\beta$ $=-.14, p<.01)$ and education $(\beta=-.15, p<.01)$ were significant indicators of cancer screening. Ethnic identity ( $\beta=.10, p<.05)$ and self-esteem $(\beta=.23, p<.001)$ were entered next (Model II), and accounted for $10 \%$ of the total variance. When entered, the effect of education remained as a significant indicator $(\beta=-.15, p<.01)$ in Model II, however age was not retained. Table 3 shows that after controlling for the demographic characteristics, and ethnic identity and self-esteem variables; the social variables (masculinity, avoidance-attachment, anxiousattachment Model III) accounted for another $30 \%$ of the model's variance. The effect of education, ethnic identity, and self-esteem remained significant when the social indicators were included in the analyses.

Table 3. Predictors of cancer screening among Black men.

\begin{tabular}{|c|c|c|c|}
\hline & & Model & \\
\hline Variable & Model 1 & Model 11 & Model 111 \\
\hline \multicolumn{4}{|l|}{ Demographic } \\
\hline Age & .00 & -.09 & $-.14^{* *}$ \\
\hline Education & $-.17^{*}$ & $-.15^{* *}$ & $-.15^{* *}$ \\
\hline $\mathrm{R}^{2}$ & .05 & & \\
\hline Adjusted $\mathrm{R}^{2}$ & .04 & & \\
\hline $\mathrm{R}^{2}$ change & .05 & & \\
\hline $\mathrm{P}$ value & $<0.0001$ & & \\
\hline \multicolumn{4}{|l|}{ Social } \\
\hline Identity & $.09^{* *}$ & $.10^{* *}$ & \\
\hline Self-esteem & $.16^{* *}$ & $.23^{*}$ & \\
\hline $\mathrm{R}^{2}$ & .11 & & \\
\hline Adjusted $\mathrm{R}^{2}$ & .10 & & \\
\hline $\mathrm{R}^{2}$ change & .06 & & \\
\hline$P$ value & $<.0001$ & & \\
\hline \multicolumn{4}{|l|}{ Health } \\
\hline Masculinity & $-.28^{*}$ & & \\
\hline Avoidance attachment & $.37^{*}$ & & \\
\hline Anxious Attachment & $-.19^{*}$ & & \\
\hline $\mathrm{R}^{2}$ & .31 & & \\
\hline Adjusted $\mathrm{R}^{2}$ & .30 & & \\
\hline $\mathrm{R}^{2}$ change & .21 & & \\
\hline P value & $<0.0001$ & & \\
\hline
\end{tabular}

${ }^{*} p<.01 ;{ }^{* *} p<.05$. 
The full regression model was significant $(F[7,359]=22.93, p<0.001)$ and accounted for $56 \%$ of the total variation in cancer screening. When the three models were included in the final analysis, education $(\beta=-.17, p$ $<0.001)$, ethnic identity $(\beta=.09, p<0.05)$, self-esteem $(\beta=.16, p=0.01)$, masculinity $(\beta=-.28, p<.001)$, avoidance-attachment $(\beta=.37, p<0.001)$, and anxious-attachment $(\beta=-.19, p<0.001)$ were significant indicators of cancer screening among Black men.

\subsection{Comparison of Age Groups on Cancer Screening}

Although age differences in perceptions of cancer screening is not the primary focus of this investigation, but of interest, comparison of means were analyzed. An independent-samples $t$-test was conducted to compare cancer screening between younger Black men ( $<31$ years of age) and those $31+$ years (using 31 as the median age). There was a significant difference in the scores of cancer screening between the older $(\mathrm{M}=1.35, \mathrm{SD}=1.27)$ and younger $(\mathrm{M}=1.75, \mathrm{SD}=1.15)$; $\mathrm{t}(-3.18)=367, p<.05)$ Black men. The older cohort also differed significantly from younger Blacks in conformity to masculinity beliefs $(\mathrm{t}(2.49)=367, p<.01)$, self-esteem $(\mathrm{t}(-3.42)=366$, $\mathrm{p}=.001)$, and avoidance-attachment $(\mathrm{t}(-3.12)=367, p<.05)$. These results suggest that the older Black men are less likely to screen for cancer, more likely to conform to masculinity beliefs, have lower self-esteem, and are lower on avoidance-attachment than the younger Black men. Findings from these analyses suggest that important factors concerning the knowledge, belief about cancer diagnoses, and screening for cancer may vary by age (Table 4).

\section{Discussion}

The health status of minority males in the United States has been described as an all-pervasive crisis (US Department of Health and Human Services [DHHS], 2013; Williams, 2003). This has been noticeably characterized with the increased rates of disability, morbidity, and mortality of minority males compared with their raced and gendered counterparts (Williams, 2003). To fully understand the dynamics of this issue, data show that Black American men have a life expectancy similar to that of males in El Salvador, Iran, and Viet Nam (Gadson, 2006), The significance of this comparison, to that of individuals in "third world" countries, is also evident in the diagnosis, treatment, and management of many chronic health conditions (Calvert \& Isaac-Sagave, 2013; Calvert, Isaac, \& Johnson, 2012). This is a reflection of a paradoxical health disparities paradigm: being a Black man. Addressing these domains is convoluted and remains as an untapped area of discussion. To understand the mechanisms by which adult Black males experience health, efforts are needed to identify constructs (e.g., access to health care, health-related behaviors) that influence their daily-lived experiences.

Findings from the current investigation supplement prior research underscoring the importance socio-cultural factors have on health and health behaviors (Zamora \& Clingerman, 2011). Data from the current investigation address how identified social factors (e.g., masculinity, ethnic identity, self-esteem, and attachment styles) influence current cancer screening among Black men. This makes a significant contribution considering that these factors have not collectively been investigated among this marginalized adult population.

Interesting data from this study showed education as is a significant indicator of cancer screening, where those with less years of education being less likely to be screened for cancer. This corresponds with the long

Table 4. Age group comparisons on cancer screening.

\begin{tabular}{cc}
\hline Variables & $t$-test \\
\hline Cancer screening & $-3.18^{*}$ \\
Masculinity & $2.49^{*}$ \\
Identity & -1.92 \\
Self-esteem & $-3.42^{*}$ \\
Avoidance attachment & $-3.12^{* *}$ \\
Anxious attachment & -.48 \\
\hline
\end{tabular}

$$
{ }^{*} p<.01 ;{ }^{* *} p<.05 \text {. }
$$


history of data indicating the significance education has on health outcomes, access to care, treatment options, and participation in health preventive behaviors (Baker et al., 2016; Baker \& Whitfield, 2006; Glanz, Rimer, \& Viswanath, 2008). The additive advantage of education is having the ability to garner the knowledge and skills needed to manage one's health. Recent data support this concept in acknowledging the positive relationship between cancer knowledge and taking the necessary steps to be screened for cancer (Welch \& Albertsen, 2009). Similarly, it is suggested that those with higher education actively seek information regarding their health and health status (Mayer et al., 2007). This may seem intuitive; suggesting the positive association between education and health/cancer screening. Yet, if this is the case, why are there not more individuals, particularly those with more than 12 years of education, being screened for cancer? The question remains, what can be done to counter what is provided in the literature to what is actually being applied and practiced in the community. This is particularly relevant among Black men. Although data from this study coincides with the current literature, there remains the need to reach a much diverse gendered audience. Resources are needed in the communities that provide access to these men. Yet, what is all the more critical is providing services that are of quality, and are acceptable, accessible, and available. When these factors are addressed, then can we then begin to attend to the desperate needs to Black men, particularly when addressing the importance and benefits of taking the precautionary measures to be screened for cancer.

This begins to address yet another important issue around Black men and health. Results from this investigation corroborate with the current literature acknowledging the role masculinity and masculine beliefs have on the well-being of men. Finding the significant association between masculinity and current cancer screening is consistent with the current data showing the influence these contextual notions have on decision-making. Recent reports document the significant association with high conformity to masculinity beliefs and less engagement in preventive health (Mahalik, Burns, \& Syzdek, 2007; Mahalik \& Burns, 2011). The observed conformity to masculinity roles may be due to the differences in societal expectations and their lived experiences as Black men. More importantly, these objectified ideas are recognized as cautionary and ill-stated expectations.

Understanding the contextual patterning of the meaning behind masculinity and the authorityit carries in making certain health-related decisions is vital. For the observed relationship between conformity and cancer screening, there is the possibility of differences in the type of health information and messages that are being delivered to Black men. Other recent data showed that health information, especially from the media, usually portray cancer as being predominantly a White problem (Brodie, Kjellson, Hoff, \& Parker, 1999). These social orientations and structural domains combine to increase health risks and risk-taking behaviors, emotional distress, and diminished health promoting behaviors (Mahalik, Pierre, \& Wan, 2006). Yet, being aware of such allows systemic changes, whereby negative outcomes can be channeled to that of more protective behaviors and health outcomes.

As evidenced, identifying with one's ethnic group is crucial for health behavior, where, for this investigation, Black men who strongly identified as Black and/or with their "Black culture" may be more inclined to engage in cancer screening compare to those who do not. While there is an increased interest documenting the needs of Black men, there remains a dearth of information acknowledging the influence ethnic identity has on the health among men. Identification with one's ethnic/racial group has traditionally been associated with willingness to accept health messages or engage in healthy behaviors (Jetten, Haslam, \& Alexander, 2012, Lumpkins, Vancy, Baker, Daley, Ndikum-Moffer, \& Greiner, 2015).

Conversely, distrust of motives and health information emanating from outside of the racial group may have a negative impact on the preventive health, causing Black men to reject being screened for cancer (Dovidio \& Fiske, 2012). By recognizing the historical context of this mistrust, we may begin to identify strategies that acknowledges the relevancy of their mistrust.

To our knowledge, this is the one of few investigations examining the association of self-esteem, attachment (avoidance and anxious), and cancer screening. While the relationship between self-esteem being associated with ill health (Marmot, 2003) has been examined among the general population, few data are available highlighting this relationship among Black men. Exploring the extent to which a person's perceived self-worth dictates their actions towards preventive health may present for a better understanding of reasons for those behaviors. Higher self-esteem may will lead to confidence in engaging in health behavior (in this case, cancer screening) and avoiding health detrimental acts. Thus, low self-esteem results in possible avoidance to engage in cancer screening. These findings should be useful for researchers seeking to understand why people resist beneficial health information, and for practitioners who aim to create interventions that may reduce such resistance. 
Similarly, attachment style was a significant factor in cancer screening. Empirical evidence shows secure attachment as a valuable and effective health intervention tool, which when used together with health promotion materials, can be extremely useful (Huntsinger \& Luecken, 2004). Specific to this investigation, it is suggested that Black men who are less anxious about establishing relationships, and who worry less about abandonment, will report higher participation in cancer screening. Being securely attached can counter internalized masculinity norms and increase Black men's willingness to engage in cancer screening. Understanding attachment trends among this target group may increase the understanding of symptomatic outcomes and health seeking behavior(s), while reducing negative perceptions.

Although this study demonstrated important and significant results focusing on cancer screening among Black men, some limitations must be acknowledged. First, this was a cross-sectional study; therefore, changes over time in reported cancer knowledge, cancer screening behaviors, and diagnoses could not be determined. Another limitation was the higher number of younger Black men within the sample. The majority of the sample were men under the age of 50; therefore, our ability to generalize these findings to older men, particularly those at the age where cancer is more prevalent, is limited. Additionally, the data were collected via self-reports that may result in potential reporting bias such as social desirability. Reactions to social desirability may have yielded responses that were favorable to that of the men. Finally, our inclusion criteria was not limited to a specific cancer screening (e.g., prostate, colorectal, skin); therefore, we cannot definitively compare our findings with other studies examining specific cancer screening. Despite these limitations, our findings make a significant contribution to the literature as it explores trends in the incidences and health perceptions among Black men.

\section{Conclusion}

Cancer is a complex and multi-dimensional illness, by which prognosis may be influenced by psychological and social variables. Utilizing a biopsychosocial approach provides a comprehensive understanding of the biological, psychological, and social issues involved in the incidences of cancer (Gatchel, 2004). Despite campaigns to early cancer detection, additional efforts are needed to effectively get Black men to screen for cancer. An area of improvement is a more in-depth and tailored assessment to reach a decisive understanding of the influence social determinants of health heave among Black men. As evidenced in this study, understanding predictors impeding preventive health behaviors among Black men, while examining and correcting misconceptions of cancer diagnoses, are desperately needed. Taking this necessary step may decrease the barriers to cancer screening, and thus promoting early detection, while leading to living a longer and healthier life.

\section{References}

Addis, M. E., \& Mahalik, J. R. (2003). Men, Masculinity and the Contexts of Help Seeking. American Psychologist, 58, 514. http://dx.doi.org/10.1037/0003-066X.58.1.5

Armitage, C. J., \& Harris, P. R. (2006). The Influence of Adult Attachment on Symptom Reporting: Testing a Mediational Model in a Sample of the General Population. Psychology and Health, 21, 351-366. http://dx.doi.org/10.1080/14768320500223479

Baker, T. A., \& Whitfield, K. E. (2006). Physical Functioning in Older Blacks: An Exploratory Study Identifying Psychosocial and Clinical Predictors. Journal of the National Medical Association, 98, 1114-1120.

Baker, T. A., Roker, R., Collins, H. R., Johnson-Lawrence, V., Thorpe, R. J., Mingo, C. A., \& Vasquez, E. (2016). Beyond Race and Gender: Measuring Behavioral and Social Indicators of Pain Treatment Satisfaction in Older Black and White Cancer Patients. Gerontology \& Geriatric Medicine, 1-8. http://dx.doi.org/10.1177/2333721415625688

Bowlby, J. (1982). Attachment and Loss: Retrospect and Prospect. American Journal of Orthopsychiatry, 52, 664. http://dx.doi.org/10.1111/j.1939-0025.1982.tb01456.x

Braveman, P. (2015). Health Inequalities by Class and Race in the US: What Can We Learn from the Patterns? Social Science \& Medicine, 74, 665-667. http://dx.doi.org/10.1016/j.socscimed.2011.12.009

Brodie, M., Kjellson, N., Hoff, T., \& Parker, M. (1999). Perceptions of Latinos, African Americans, and Whites on Media as a Health Information Source. Howard Journal of Communication, 10, 147-167. http://dx.doi.org/10.1080/106461799246799

Calnan, M., \& Rutter, R. (1986). Preventive Health Practices and Their Relationship with Socio-Demographic Characteristics. Health Educational Resources, 1, 247-253. http://dx.doi.org/10.1093/her/1.4.247

Calvert, W. J., \& Isaac-Savage, E. P. (2013). Motivators and Barriers to Participating in Health Promotions Behaviors in 
Black Men. Western Journal of Nursing Research, 35, 829-848. http://dx.doi.org/10.1177/0193945913480429

Calvert, W. J., Isacc, E. P., \& Johnson, S. (2012). Health-Related Quality of Life and Health-Promoting Behaviors in Black men. Health \& Social Work, 37, 19-27. http://dx.doi.org/10.1093/hsw/hls001

Centers for Disease Control. (2014). Leading Causes of Death in Males United States. http://www.cdc.gov/men/lcod/

Ciechanowski, P. S., Walker, E. A., Katon, W. J., \& Russo, J. E. (2002). Attachment Theory: A Model for Health Care Utilization and Somatization. Psychosomatic Medicine, 64, 660-667.

Ciechanowski, P., Sullivan, M., Jensen, M., Romano, J., \& Summers, H. (2003). The Relationship of Attachment Style to Depression, Catastrophizing and Health Care Utilization in Patients with Chronic pain. Pain, 104, 627-637. http://dx.doi.org/10.1016/S0304-3959(03)00120-9

Courtenay, W. H. (2000). Engendering Health: A Social Constructionist Examination of Men’s Health Beliefs and Behaviors. Psychology of Men \& Masculinity, 1, 4-15. http://dx.doi.org/10.1037/1524-9220.1.1.4

Delva, J., O’Malley, P., \& Johnston, L. (2006). Racial/Ethnic and Socioeconomic Status Differences in Overweight and Health-Related Behaviors among American Students: National Trends 1986-2003. Journal of Adolescent Health, 39, 536545. http://dx.doi.org/10.1016/j.jadohealth.2006.02.013

Dovidio, J. F., \& Fiske, S. T. (2012). Under the Radar: How Unexamined Biases in Decision-Making Processes in Clinical Interactions Can Contribute to Health Care Disparities. American Journal of Public Health, 102, 945-952. http://dx.doi.org/10.2105/AJPH.2011.300601

Ellemers, N., \& Haslam, S. A. (2011). Social Identity Theory. Handbook of Theories of Social Psychology, 2, 379-398.

Feeney, J. A. (2000). Implications of Attachment Style for Patterns of Health and Illness. Child: Care, Health and Development, 26, 277-288. http://dx.doi.org/10.1046/j.1365-2214.2000.00146.x

Gadson, S. L. (2006). The third World Health Status of Black American Males, Journal of the National Medical Association, $98,488-491$.

Gatchel, R. J. (2004). Comorbidity of Chronic Pain and Mental Health Disorders: the Biopsychosocial Perspective. American Psychologist, 59, 795-805. http://dx.doi.org/10.1037/0003-066X.59.8.795

Glanz, K., Rimer, B. K., \& Viswanath, K. (Eds.). (2008). Health Behavior and Health Education: Theory, Research, and Practice. New York: John Wiley \& Sons.

Harrison, J., Chin, J., \&Ficarrotto, T. (1992). Warning: Masculinity May Be Dangerous to Your Health. In M. S. Kimmel, \& M. A. Messner (Eds.), Men’s Lives (pp. 271-285). New York: Macmillan Press.

Haslam, S. A., Jetten, J., Postmes, T., \& Haslam, C. (2009). Social Identity, Health and Well-Being: An Emerging Agenda for Applied Psychology. Applied Psychology, 58, 1-23. http://dx.doi.org/10.1111/j.1464-0597.2008.00379.x

Himmelstein, M. S., \& Sanchez, D. T. (2014). Masculinity Impediments: Internalized Masculinity Contributes to Healthcare Avoidance in Men and Women. Journal of Health Psychology, Published Online before Print.

http://dx.doi.org/10.1177/1359105314551623

Huntsinger, E. T., \& Luecken, L. J. (2004). Attachment Relationships and Health Behavior: The Mediational Role of SelfEsteem. Psychology \& Health, 19, 515-526. http://dx.doi.org/10.1080/0887044042000196728

Jetten, J., Haslam, C., \& Alexander, S. H. (Eds.). (2012). The Social Cure: Identity, Health and Well-Being. Psychology Press.

Kaplan, M., Newson, J., McFarland, B., \& Lu, L. (2001). Demographic and Psychosocial Correlates of Physical Activity in Late Life. American Journal of Preventive Medicine, 21, 306-312. http://dx.doi.org/10.1016/S0749-3797(01)00364-6

Laverie, D. A. (1998). Motivations for Ongoing Participation in a Fitness Activity. Leisure Sciences, 20, 277-302. http://dx.doi.org/10.1080/01490409809512287

Levant, F., Hall, J., \& Rankin, T. (2013). Male Role Norms Inventory-Short Form (MRNI-SF): Development, Confirmatory Factor Analytic Investigation of Structure, and Measurement Invariance across Gender. Journal of Counselling Psychology, 60, 228-238. http://dx.doi.org/10.1037/a0031545

Levin, B., Lieberman, D. A., McFarland, B., Smith, R. A., Brooks, D., Andrews, K. S., Pickhardt, P., et al. (2008). Screening and Surveillance for the Early Detection of Colorectal Cancer and Adenomatous Polyps, 2008: A Joint Guideline from the American Cancer Society, the US Multi-Society Task Force on Colorectal Cancer, and the American College of Radiology. CA: Cancer Journal for Clinicians, 58, 130-160. http://dx.doi.org/10.3322/ca.2007.0018

Lo, C., Walsh, A., Mikulincer, M., Gagliese, L., Zimmermann, C., \& Rodin, G. (2009). Measuring Attachment Security in Patients with Advanced Cancer: Psychometric Properties of a Modified and Brief Experiences in Close Relationships Scale. Psycho-Oncology, 18, 490-499. http://dx.doi.org/10.1002/pon.1417

Lumpkins, C. Y., Vanchy M. S., Baker, T. A., Daley, C., Ndikum-Moffor, F. \& Greiner, K. A. (2015). Marketing a Healthy Mind, Body and Soul-An Analysis of How African American Men View the Church as a Social Marketer and Health 
Promoter of Colorectal Cancer Risk and Prevention. Health Education \& Behavior, Epub Ahead of Print. http://dx.doi.org/10.1177/1090198115604615

Mahalik, J. R., \& Burns, S. M. (2011). Predicting Health Behaviors in Young Men That Put Them at Risk for Heart Disease. Psychology of Men \& Masculinity, 12, 1-12. http://dx.doi.org/10.1037/a0021416

Mahalik, J. R., Burns, S. M., \& Syzdek, M. (2007). Masculinity and Perceived Normative Health Behaviors as Predictors of Men’s Health Behaviors. Social Science \& Medicine, 64, 2201-2209. http://dx.doi.org/10.1016/j.socscimed.2007.02.035

Mahalik, J. R., Pierre, M. R., \& Wan, S. S. C. (2006). Examining Racial Identity and Masculinity as Correlates of Self-Esteem and Psychological Distress in Black Men. Journal of Multicultural Counseling and Development, 34, 94-104. http://dx.doi.org/10.1002/j.2161-1912.2006.tb00030.x

Mankowski, E. S., \& Maton, K. I. (2010). A Community Psychology of Men and Masculinity: Historical and Conceptual Review. American Journal of Community Psychology, 45, 73-86. http://dx.doi.org/10.1007/s10464-009-9288-y

Marmot, M. (2003). Self-Esteem and Health: Autonomy, Self-Esteem, and Health Are Linked Together. BMJ, 327, $574-575$. http://dx.doi.org/10.1136/bmj.327.7415.574

Marmot, M. (2005). Social Determinants of Health Inequalities. Lancet, 365, 1099-1104. http://dx.doi.org/10.1016/S0140-6736(05)74234-3

Marmot, M., Friel, S., Bell, R., Houweling, T. A. J., \& Taylor, S. (2008). Closing the Gap in a Generation: Health Equity through Action on the Social Determinants of Health. Lancet, 372, 1661-1669. http://dx.doi.org/10.1016/S0140-6736(08)61690-6

Mayer, D. K., Terrin, N. C., Kreps, G. L., Menon, U., McCance, K., Parsons, S. K., \& Mooney, K. H. (2007). Cancer Survivors Information Seeking Behaviors: A Comparison of Survivors Who Do and Do Not Seek Information about Cancer. Patient Education and Counseling, 65, 342-350. http://dx.doi.org/10.1016/j.pec.2006.08.015

Mikulincer, M., \& Shaver, P. R. (2007). Boosting Attachment Security to Promote Mental Health, Prosocial Values, and Inter-Group Tolerance. Psychological Inquiry, 18, 139-156. http://dx.doi.org/10.1080/10478400701512646

National Cancer Institute (2016). Surveillance, Epidemiology, and End Results Program, Fast Facts, Age-Adjusted SEER Incidence Rates by Sex All Sites All Ages. http://seer.cancer.gov/statfacts/html/prost.html

Oyserman, D., Fryberg, S. A., \& Yoder, N. (2007). Identity-Based Motivation and Health. Journal of Personality and Social Psychology, 93, 1011-1027. http://dx.doi.org/10.1037/0022-3514.93.6.1011

Rosenberg, M. (1965). Society and the Adolescent Self-Image. Princeton, NJ: Princeton University Press.

Sakaluk, J. K., \& Gillath, O. (2015). The Causal Effects of Relational Security and Insecurity on Condom Use Attitudes and Acquisition Behavior. Archives of Sexual Behavior, 45, 339-352. http://dx.doi.org/10.1007/s10508-015-0618-x

Schulz, A., \& Northridge, M.E. (2004). Social Determinants of Health: Implications for Environmental Health Promotion. Health Education \& Behavior, 31, 455-470. http://dx.doi.org/10.1177/1090198104265598

Simpson, J. A., Rholes, W. S., Oriña, M. M., \& Grich, J. (2002). Working Models of Attachment, Support Giving, and Support Seeking in a Stressful Situation. Personality and Social Psychology Bulletin, 28, 598-608. http://dx.doi.org/10.1177/0146167202288004

Smith, R. A., Cokkinides, V., von Eschenbach, A. C., Levin, B., Cohen, C., Runowicz, C. D., Eyre, H. J., et al. (2002). American Cancer Society Guidelines for the Early Detection of Cancer. CA: Cancer Journal for Clinicians, 52, 8-22. http://dx.doi.org/10.3322/canjclin.52.1.8

Tajfel, H. (1972). Experiments in a Vacuum. In J. Israel, \& H. Tajfel (Eds.), The Context of Social Psychology: A Critical Assessment (pp. 69-119). London: Academic Press.

US Department of Health and Human Services, Office of Minority Health (2013). Profile: Black/African Americans. http://minorityhealth.hhs.gov/omh/browse.aspx?lvl=3\&lvlid=61

Warner, D. F., \& Brown, T. H (2011). Understanding How Race/Ethnicity and Gender Define Age-Trajectories of Disability: An Intersectionality Approach. Social Science \& Medicine, 72, 1236-1248. http://dx.doi.org/10.1016/j.socscimed.2011.02.034

Welch, H. G., \& Albertsen, P. C. (2009). Prostate Cancer Diagnosis and Treatment after the Introduction of Prostate-Specific Antigen Screening: 1986-2005. Journal of the National Cancer Institute, 101, 1325-1329. http://dx.doi.org/10.1093/jnci/djp278

Williams, D. R. (2003). The Health of Men: Structured Inequalities and Opportunities. American Journal of Public Health, 93, 724-731. http://dx.doi.org/10.2105/AJPH.93.5.724

Williams, D. R., Neighbors, H. W., \& Jackson, J. S. (2003). Racial/Ethnic Discrimination and Health: Findings from Community Studies. American Journal of Public Health, 93, 200-208. http://dx.doi.org/10.2105/AJPH.93.2.200

Zamora, H., \& Clingerman, E. M. (2011). Health Literacy among Older Adults: A Systematic Literature Review. Journal of Gerontological Nursing, 37, 41-51. http://dx.doi.org/10.3928/00989134-20110503-02 


\section{Submit or recommend next manuscript to SCIRP and we will provide best service for you:}

Accepting pre-submission inquiries through Email, Facebook, Linkedin, Twitter, etc A wide selection of journals (inclusive of 9 subjects, more than 200 journals)

Providing a 24-hour high-quality service

User-friendly online submission system

Fair and swift peer-review system

Efficient typesetting and proofreading procedure

Display of the result of downloads and visits, as well as the number of cited articles

Maximum dissemination of your research work

Submit your manuscript at: http://papersubmission.scirp.org/ 